\title{
Pit and fissure sealant retention
}

\author{
Abstracted from \\ Kühnisch J, Mansmann U, Heinrich-Weltzien R, Hickel R. \\ Longevity of materials for pit and fissure sealing-Results from a meta-analysis. \\ Dent Mater 2012; 28: 298-303. 2011 Dec 3. [Epub ahead of print] \\ Address for correspondence: J. Kühnisch, Ludwig-Maximilians-Universität München, \\ Poliklinik für Zahnerhaltung und Parodontologie, Goethestraße 70, 80336 München, Germany. \\ E-mail: jkuehn@dent.med.uni-muenchen.de
}

\section{Question: Which type of sealant is retained longest?}

Data sources The Cochrane Central Register of Controlled Trials (CENTRAL) and Medline were searched. Manufacturers of dental floss were also contacted to identify any trials.

Study selection Only clinical trials and field studies of two years or longer were included.

Data extraction and synthesis The studies were analysed to determine the retention rates of the various materials studied (UV-light-, light- and auto-polymerising resin-based sealants, fluoride-releasing materials, compomers, flowable composites and glass-ionomer-cement-based sealants). A meta-analysis was conducted using a random effects model for longitudinal logistic regression and Bayesian statistics.

Results Ninety-eight clinical reports and 12 field trial reports were identified; 49 trials used random allocation. Auto-polymerising sealants had the observation time of up to 20 years. \% year retention rates are shown in the table. Retention rates for UV-light-polymerising materials, compomers and glass-ionomer-cement-based sealants (5-year retention rates were $<19.3 \%$ ) were poor, while retention rates for UV-light-polymerising materials, compomers and glass ionomer cement-based sealants were classified as inferior.

\begin{tabular}{|l|l|l|} 
& $\begin{array}{l}\mathbf{5 - y e a r} \\
\text { retention rate }\end{array}$ & $\begin{array}{l}\mathbf{9 5 \%} \text { confidence } \\
\text { Interval }\end{array}$ \\
\hline Auto-polymerising sealants & $64.7 \%$ & $57.1-73.1 \%$ \\
\hline $\begin{array}{l}\text { Resin-based light-polymerising } \\
\text { sealants }\end{array}$ & $83.8 \%$ & $54.9-94.7 \%$ \\
\hline Fluoride-releasing products & $69.9 \%$ & $51.5-86.5 \%$ \\
\hline
\end{tabular}

Conclusions This meta-analysis suggested that resin-based sealants can be recommended for clinical use. The faster and less error-prone clinical application of light-polymerising materials, however, makes them the preferred choice for daily dental practice.

\section{Commentary}

This paper presents the results of a systematic review examining the evidence for the retention of different pit and fissure sealant (sealant) materials. The article has in addition to the published paper on-line tables giving further details, which is clearly useful and overcomes the problem of presenting a systematic review in an accessible way.

There are a number of existing systematic reviews examining the retention, effectiveness and choice of material. ${ }^{1-4}$ These include a Cochrane Systematic Review. ${ }^{1}$ This leads to the question of whether we need another systematic review, and what does this paper add? This systematic review and meta-analysis does differ in that it uses a random effects model for longitudinal logistic regression and Bayesian statistics to calculate retention rates over time.

The search and data abstraction methods adhere to the standard methods and are therefore sound. Randomised clinical trials and field trials of at least two years' duration were included, longer than the one year inclusion criteria of the Cochrane Review. Sealant materials reported included: UV-light polymerising resins (27); autopolymerising resins (47); light-polymerising resins (32); fluoridereleasing resins (15); flowable composites (3); compomers (7); and glass-ionomer sealants(34).

It is difficult to understand why UV-light materials were included in the review as these are now obsolete. The first meta-analysis on sealants clearly demonstrated that these were inferior so their inclusion adds nothing. ${ }^{2}$

One hundred and ten trials met the inclusion criteria. It is crucial to know how many papers the results and conclusions of each element of the review are based on and this is not reported. To find this the reader has to go on-line and count the individual references in each table. The results of this process are presented in brackets above.

Many trials do not report caries prevention, the true outcome in question, but use retention as a proxy. This systematic review takes this approach and although this surrogate outcome for caries prevention may have some validity for resin sealants, this is not the case for glass ionomer materials, where poor retention is well recognised but the question and doubt rests around whether there is a residual caries preventive effect due to fluoride release. ${ }^{4}$ This review does not add to this debate.

The findings are that resin materials, including fluoride containing materials either auto- or light-polyerising materials, have the highest retention rates at 2, 3 or 5 years. The reported retention for light-polymerising sealants was $83.8 \%$ (95\% C.I. 54.9-94.7). All resin 


\section{CARIES}

materials retention rates reported are higher than the Cochrane Review's $52 \%$ at four years. ${ }^{1}$ Glass ionomer sealants had a two year retention figure of $12.3 \%$ (95\% C.I. 7.6-19.0). The review did not report separately for type of glass ionomer material, conventional or resin modified or for curing method, which is surprising given the multiple analyses of resin materials.

Overall, although all evidence is worthwhile gathering and reporting, it is not clear what this review adds to our knowledge

\section{Practice points}

- Resin sealant materials have higher retention rates than glass ionomers

- Light cured resins are the most practical to use

- Glass ionomer sealants have poor retention rates even at two years and certainly its findings do not have the potential to alter current guidelines on clinical practice.

\section{Chris Deery \\ School of Clinical Dentistry, University of Sheffield, Sheffield, UK}

1. Ahovuo-Saloranta A, Hiiri A, Nordblad A, Mäkelä M, Worthington HV. Pit and fissure sealants for preventing dental decay in the permanent teeth of children and adolescents. Cochrane Database Syst Rev 2008; (4): CD001830.

2. Llodra JC, Bravo M, Delgado-Rodriguez M, Baca P, Galvez R. Factors influencing the effectiveness of sealants - a meta-analysis. Community Dent Oral Epidemiol 1993; 21: $261-268$.

3. Mejare I, Lingström P, Petersson LG, et al. Caries-preventive effect of fissure sealants: a systematic review. Acta Odontol Scand 2003; 61: 321-330.

4. Yengopal V, Mickenautsch S, Bezerra AC, Leal SC. Caries-preventive effect of glass ionomer and resin-based fissure sealants on permanent teeth: a meta analysis. Joral Sci 2009; 51: 373-382.

Evidence-Based Dentistry (2012) 13, 9-10. doi:10.1038/sj.ebd.6400837 